Boise State University

ScholarWorks

Psychological Sciences Faculty Publications and

Presentations

Department of Psychological Science

$11-1-2010$

\title{
Image and Video Disclosure of Substance Use on Social Media Websites
}

Elizabeth M. Morgan

Boise State University

Chareen Snelson

Boise State University

Patt Elison-Bowers

Boise State University

\section{(c) $\oplus \Theta \Theta$}

This is an author-produced, peer-reviewed version of this article. (C) 2009, Elsevier. Licensed under the Creative Commons AttributionNonCommercial-NoDerivatives 4.0 International License (https://creativecommons.org/licenses/by-nc-nd/4.0/). The final, definitive version of this document can be found online at Computers in Human Behavior, doi: 10.1016/j.chb.2010.04.017 


\title{
Image and Video Disclosure of Substance Use on Social Media Websites
}

\author{
Elizabeth M. Morgan, Chareen Snelson, and Patt Elison-Bowers \\ Boise State University
}

\begin{abstract}
The present study examines young adults' use of social media websites, such as MySpace, Facebook, and YouTube, to post public images and videos of themselves depicting alcohol consumption, inebriated behavior, or recreational marijuana use. A content analysis revealed that the majority of image and video representations of alcohol consumption depicted females in social gatherings while images and videos depicting marijuana use depicted solitary males. Videos typically were viewed frequently and gained positive ratings. Among a sample of college students, one-third of participants reported having posted a picture depicting substance use on a social networking site, with 97 percent aware that others engage in this phenomenon. Students' perceptions of alcohol-related postings were generally positive or seen as a matter of individual choice while marijuanarelated postings were generally viewed more negatively.
\end{abstract}

Keywords: Social networking, MySpace, Facebook, YouTube

Social media websites such as MySpace, Facebook, and YouTube have grown rapidly in recent years making it easier than ever to both view and distribute personal media on the Web. Facebook users logged over 13.9 billion minutes during April 2009 and MySpace users logged over 4.9 billion minutes (Nielson Wire, 2009). YouTube surpassed 100 million U.S. viewers for the first time in March 2009 (comScore, 2009) and in October 2009 the number had soared to 1 billion (Hurley, 2009). Indeed, college students frequently use social networking websites: One study found that college students reported visiting social network profiles an average of 2.4 to 4.19 times a day for an average of one to two and a half hours (Moreno, et al., 2009; Raacke \& Bonds-Raacke, 2008).

College students report using social networking websites to make new friends, locate old friends and to keep in touch with current friends (Raacke \& Bonds-Raacke, 2008). Social network profiles also provide an avenue for identity construction and representation, usually in the form of "showing” rather than "telling” (Zhao, Grasmuch, \& Martin, 2008). Despite the positive outcomes of using social networking websites, such as feelings of mastery, identity exploration, and peer group interaction (Hinduja \& Patchin, 2007; Schmitt, Dayanim, \& Matthias, 2008), online social networking activities can also include less positive activities. Several studies have identified that as many as half of all adolescents and young adults with social networking profiles display negative health risk behaviors, including sexual behaviors and substance use (Moreno, Parks, \& Richardson, 2007; Moreno, Parks, Zimmerman, Brito, \& Christakis, 2009). Moreno, et al. (2009) found that 85\% of young adult's publicly accessible MySpace profiles displayed substance use references.

Any number of problems can result from posting images of health risk behaviors including increased risk of cyberbullying, damage to reputation, or loss of educational or vocational opportunities (Barnes, 2009; SkillStorm, 2009; Inside Higher Ed, 2009; Ybarra, et al., 2007). Additionally, the presence of these images may increase peer acceptance and interest in the risk behaviors (Bandura, 2004). Furthermore, a variety of news sources report that police use Facebook, YouTube, and other social-media sites to catch criminals who discuss or upload video recordings of their illegal acts for public viewing (Boston Globe, 2009; Fox News, 2007; New York Times, 2010). Because both photographs and video record an exact representation of real-world events and may be viewed repeatedly, when they are uploaded to a publicly accessible social networking or video-sharing site, images and video footage becomes available to a worldwide audience of Internet users. Risks for accessibility and permanent documentation of alcohol consumption, inebriated behavior, and marijuana use are thus exponentially greater for adolescents and young adults who engage in this phenomenon. 
NOTICE: This is the author's version of a work accepted for publication by Elsevier. Changes resulting from the publishing process, including peer review, editing, corrections, structural formatting and other quality control mechanisms, may not be reflected in this document. Changes may have been made to this work since it was submitted for publication. The definitive version has been published in Computers in Human Behavior, Volume 26, Issue 6, 2010. DOI: 10.1016/j.chb.2010.04.017

Despite the potential negative outcomes for adolescents and young adults who chose to make images of substance use publicly available, little research has examined this recent phenomenon. To address the gaps in understanding of this phenomenon, the present study seeks to identify and describe the types of publicly available images and videos depicting alcohol and marijuana use on MySpace and YouTube as well as understand the frequency of and attitudes towards this behavior among a sample of young adult college students.

\section{Self-Disclosure Online}

Research has indicated that adolescents and young adults tend to engage in self-disclosure online. For example, regarding recent internet trend 'blogging' (an online journal that is often made public), a 2007 study reported 72.7\% of participants blogged daily about their experiences (Guandagno, Okdie, \& Eno, 2007). Reported reasons for disclosing on blogs has included self-presentation, relationship management, information storage and sharing, entertainment, and showing off (Lee, Im, \& Taylor, 2008). Valkenburg and Peter (2007) found that perceived value of the internet for intimate self-disclosure increased with age among a sample of preadolescents and adolescents. Additionally, Fogel and Nehmad (2009) found that college students with profiles on social networking websites have greater risk-taking attitudes than those who do not.

Regarding the public availability of persona information in social networking profiles, Fogel and Nehmad (2009) found that $73 \%$ of young adults had their profile available for anyone to view, $81 \%$ used their real name on their profile, 35\% included an email address, $9 \%$ included a telephone number and $9 \%$ included a home address. Indeed, Schau \& Gilly (2003) found that individuals specifically reported wanting to create a highly representative digital self on their social networking profiles. However, Hinduja and Patchin (2008) found that while almost half of adolescent's MySpace profiles included pictures, less than 10 percent provided their full name and less than one percent provided their phone number. Though many social networking websites have privacy policies and settings, Rifon, La Rose, and Choi (2005) suggested that privacy policies are not reliable deterrents, since they are not often meticulously read. This could partially be due to young adults' lack of self awareness regarding their actual levels of self-disclosure and the possible ramifications of other accessing less-than-desirable personal information.

In addition to research indicating that adolescents are not restricting the visibility of their online profile information, research also suggests that individuals sharing information in a variety of online formats are generally motivated to provide accurate self-presentation (e.g., Lee, Im, \& Taylor, 2008; McKenna, Green, \& Gleason, 2002). For example, Gibbs, Ellison, and Heino (2006) found that individuals constructing online dating profiles consciously enhance profiles to increase positive responses while simultaneously maintaining enough accuracy with the anticipation of a future face-to-face exchange. Additionally, Ma \& Agarwal (2007) identified that individuals reported greater satisfaction with their participation in an online community when the other members of the community accurately perceived their presentation of self, thus likely contributing to the desire to provide an accurate and complete portrayal of self online. Furthermore, research indicates that individuals are not only encouraged to include accurate self-presentations online, but that reactions to deception in online communities tends to be highly negative (Joinson \& Dietz-Uhler, 2002).

Gender differences have been noted regarding online self-disclosure. Chiou (2006) found that male participants were more likely than females to engage in sexual self-disclosure online, while Magnuson and Dundes (2008) found the women were more likely to disclose having a significant other on MySpace profiles than males. Fogel and Nehmad (2009) found that men are less concerned with their online privacy, including identity information disclosure such as phone numbers and home addresses. Research has also indicated that male participants may be evaluated more positively for anti-moral statements while females were evaluated more negatively (Walther, Van Der Heide, Kim, Westerman, \& Tong, 2008). Consequently, posting practices, as well as attitudes toward and responses to postings, may vary by gender. 


\section{Present Study}

The purpose of this study was to examine the recent phenomenon of using social networking media to post publicly available images and videos of alcohol- and marijuana-related behaviors. As such, the first research goal was to explore MySpace and YouTube for the presence and content of public-access images and video clips depicting alcohol consumption, inebriation, or marijuana use. Specific research questions included: do these images and video exist and, if so, what behaviors are shown? Regarding the video clips, how much exposure, in terms of duration and number of days online is there for these video clips? Is there evidence of audience engagement with the videos such as multiple views, ratings, or comments?

The second research goal was to examine the frequency with which young adults report having posted such images or videos of themselves online, as well as how frequently friends have engaged in similar behaviors. Specific research questions included: how many participants have social networking accounts with MySpace, Facebook and YouTube and how often to they use these websites? How many participants have posted such images and videos of themselves and how many have a friend who has posted such an image or a video? The last research goal was to understand young adults' perceptions of individuals posting images or videos of alcohol or marijuana related activities on social networking websites, including general awareness of this phenomenon.

\section{Method}

\section{Content Analysis}

Content analyses of images and videos were conducted to address the first research goal. The video content analysis methodology for the present study was adapted from a pilot study of digital storytelling videos on YouTube (Snelson \& Sheffield, 2009). Historically, content analysis has been used to analyze and draw inferences from images and text, but it can be extended to other forms of media, including video. Krippendorff (2004) explained that "... works of art, images, maps, sounds, signs, symbols, and even numerical records may be included as datathat is, they may be considered as texts...” (p. 19).

Sampling unit. The sampling unit for image analyses included photographs and their captions posted on the MySpace website that were available for public viewing. The sampling unit for video analyses was a YouTube video and its viewing page, which includes the video player and several pieces of information such as video duration, number of views, number of ratings, average rating based on a one (low rating) to five (high rating) star system, comments, date of upload and a link to the channel owned by the person who uploaded the video. Only YouTube members may rate or comment on videos. The YouTube channel contains the user's profile and their age by default unless turned off in the channel settings.

Sampling methodology. The only viable method for obtaining samples of MySpace images and YouTube videos is through the use of search tools. In this study, both the images and videos were located using an advanced search interface provided by the website to refine and improve search results. The goal was to locate images and videos showing people drinking alcohol, drunk, or engaged in recreational drug use. Test searches were conducted to identify optimal search terms and settings required for a relevant and consistent sample relevant to the research questions and goals of the study. This initial testing led to the elimination of certain phrases such as "drinking," which produced videos not related to the study such as those of people drinking coffee or soda. The final search phrase contained the word "me" and at least one of the words: "stoned, wasted, hammered, weed, drunk." The video search was restricted to videos in English (to exclude foreign language videos) within the Comedy and People \& Blogs categories; no further restrictions were necessary within the image search. Results were sorted by relevance, which puts the most relevant image or video results from submission of a search query at the top of the list. This search strategy produced the most consistent results and verified the presence of image or video containing drinking, inebriated behavior, or marijuana use. 
NOTICE: This is the author's version of a work accepted for publication by Elsevier. Changes resulting from the publishing process, including peer review, editing, corrections, structural formatting and other quality control mechanisms, may not be reflected in this document. Changes may have been made to this work since it was submitted for publication. The definitive version has been published in Computers in Human Behavior, Volume 26, Issue 6, 2010. DOI: 10.1016/j.chb.2010.04.017

The official searches to obtain samples of images and videos were conducted in March 2009. The MySpace image search produced 14,145 results and the YouTube video search produced 26,000 results. The first 75 images and 75 videos available for public viewing in the search results list were selected for the sample (yielding a total of 150 media depictions). This type of sampling strategy has been used previously in studies of Internet content including a study of websites containing cystic fibrosis information (Anselmo, Lash, Stieb, \& Haver, 2004) and a study of digital storytelling videos found on YouTube (Snelson \& Sheffield, 2009). It is also consistent with the relevance sampling technique described by Krippendorff (2004).

Image and Video Coding. The 150 images and videos in the sample were reviewed by a panel of four independent coders who wrote descriptions based on observations of image and video content. The coders were specifically instructed to describe what they observed in the image or video, whether or not drugs or alcohol were visible or being consumed, what people were doing, and how they were behaving. Gender information was recorded in the image analysis. Images provide a static depiction where it is easy to count participants, whereas the sample of videos contained crowd scenes and shaky recordings that made it too difficult to obtain an accurate count. The video sample complemented the images by yielding dynamic information that could not be depicted in static images, such as slurred speech or staggering. An open coding technique was used to identify general themes, patterns, or categories in the descriptions of sampled images and videos (Strauss and Corbin, 1998). Additional video data collected included video duration in minutes and seconds, number of views, number of ratings, number of stars, number of comments, user age, and date of upload for each video. All coding was completed during the month of March, 2009. Because YouTube is a dynamic place with content constantly being changed, variations in the additional video data (i.e. number of views, ratings, stars, and comments) was combined and averaged.

\section{Questionnaire}

To address the remaining research goals, a questionnaire was used to assess the frequency of engagement in the behaviors under examination for a general population of college students.

Participants. Participants consisted of 314 undergraduate college students (157 men and 157 women). Participants' ages ranged from 18-25 ( $M=19.92)$, including 203 first-year students, 74 sophomores, 26 juniors, and 10 seniors. Participants’ racial backgrounds were predominantly European-American/White $(n=263 ; 84 \%)$.

Procedure. All participants were college students enrolled in a lower division psychology course at Western public university, and participated to fulfill a course requirement. Participants were given information about the survey and chose to participate in this study through an online educational experiment system. The title of the study was, "Internet Self-Disclosure Study" and participants were instructed to complete the survey via a secure, online survey website (http://www.qualitrics.com). The procedure, including consent, debriefing, and credit allocation, took place entirely online. After giving consent, participants completed a demographics section and a series of questions about their internet and social networking site use. Following these questions, participants completed several additional measures assessing drug and alcohol use and personality characteristics, some of which were not analyzed in this study. The entire questionnaire took approximately 40 minutes to complete.

Measures. In addition to a demographic questionnaire, participants completed series of questions assessing: social networking use, alcohol and marijuana use, personal experience posting alcohol- and marijuana-related pictures or videos on social networking websites (MySpace, Facebook, YouTube), and perceptions of posting alcohol- and marijuana-related pictures online.

Regarding social networking use, participants were asked, "Do you have any online social networking accounts? (e.g., MySpace, Facebook, Friendster, etc.).” They were also asked individually about MySpace and Facebook accounts and which account is their primary account and "How often do you visit social networking sites?" with options ranging from "once a year" to "five times or more a day". Regarding privacy and anonymity, participants were asked, "Are your accounts "private"? (e.g., only people who you give permission to can see the profile?)” and "How anonymous do you feel that your profile is that you post online?" with options ranging from "not at all anonymous" to "very anonymous". 
Alcohol and marijuana use was measured with two questions. Participants were asked "How often do you drink alcohol," with response options ranging from "never" and "I used to, but currently do not" to "once a month" and "once a week". Participants were also asked "How often do you use marijuana" with the same response options.

Personal experience with posting alcohol- and marijuana-related pictures online was assessed with six questions for both MySpace and Facebook. Three questions assessed alcohol-related pictures, including "Have you ever posted a picture of you drinking alcohol on MySpace?”, "Has a friend ever posted a picture of you drinking alcohol on MySpace?", and "Has a friend ever posted a picture of themselves drinking alcohol on MySpace?” The same three questions were posed regarding pictures on Facebook. A similar set of three questions assessed marijuana-related pictures, including "Have you ever posted a picture of you smoking marijuana on MySpace?", "Has a friend ever posted a picture of you smoking marijuana on MySpace?", and "Has a friend ever posted a picture of themselves smoking marijuana on MySpace?” Again, the same three questions were posed regarding pictures on Facebook.

Personal experience with posting alcohol- and marijuana-related videos on YouTube were assessed with six questions: "Have you ever posted a video of you drinking alcohol on YouTube?”, "Has a friend ever posted a video of you drinking alcohol on YouTube?", and "Has a friend ever posted a picture of themselves drinking alcohol on YouTube?" The same three questions were posed regarding videos in which the person was "smoking marijuana". A question also assessed if the videos the participant posted of themselves were available for public viewing.

Perceptions of posting alcohol- and marijuana-related pictures online were first assessed with two questions asking, “Are you aware that people post pictures of themselves drinking alcohol online?" and "Are you aware that people post pictures of themselves smoking marijuana online?” Next, participants were asked two open-ended questions: "What is your reaction to posting pictures of drinking alcohol online?" and "What is your reaction to posting pictures of smoking marijuana online?" Responses to these open-ended questions were reviewed for emergent themes, the frequencies of which were ascertained by independent coders.

\section{Results}

\section{Content Analysis}

MySpace Images. The image description categories are outlined in Table 1. About half of the images were related to alcohol with the other half related to marijuana use. Images included males and females alone and in groups smoking marijuana, drinking alcohol, posing with alcohol, or displaying drunken behavior. The ages of individuals in the images were estimated to be between 15-24 years old with an average age of 18. In images containing identifiable alcohol, it was mostly frequently hard alcohol $(n=18)$ and beer $(n=15)$; several images contained individuals drinking wine $(n=3)$. Twenty six pictures contained individuals smoking marijuana out of a pipe or a bong while seven included images of individuals smoking marijuana in rolled paper. Sixty two of the pictures were posted by someone who was in the picture; thirteen were posted by another individual.

YouTube Videos. The video description categories are outlined in Table 2. Sixty-four of the videos included people engaged in behaviors consistent with known effects of alcohol consumption (National Highway Traffic Safety Administration, 2005). These videos had an amateurish look with shaky video footage as if they had been recorded on portable video cameras and the surrounding suggests that they were taken during parties or other social events. Among the list of effects caused by consumption of alcohol and depicted in the videos were slurred speech, loss of muscle coordination, impaired judgment, loss of inhibition, and vomiting. Other behaviors observed in the videos included drinking from glasses and bottles on camera, statements indicating that people on camera were drunk, people playing pranks on someone else who was described as drunk, and helping another person who was described drunk. The other eleven videos differed enough that they warranted separation into their own categories; descriptions of these videos are included in Table 2. 
NOTICE: This is the author's version of a work accepted for publication by Elsevier. Changes resulting from the publishing process, including peer review, editing, corrections, structural formatting and other quality control mechanisms, may not be reflected in this document. Changes may have been made to this work since it was submitted for publication. The definitive version has been published in Computers in Human Behavior, Volume 26, Issue 6, 2010. DOI: 10.1016/j.chb.2010.04.017

The additional descriptive data for YouTube videos is shown in Table 3. The mean, standard deviation, minimum and maximum values for duration in minutes, number of views, number of ratings, number of stars, number of comments, user age, and days online from February 6, 2006 through March 2, 2009 are included. This date range extends from the oldest to the newest video in the sample. It is important to note that the number of days online contributes to variability in some of the statistics shown in Table 2 (i.e. number of views, ratings, and comments).

\section{Questionnaire}

Results from the questionnaire sampling a general population of undergraduate students indicated that almost all participants ( $n=288$; 92\%) reported having an online social networking account. Of those with social networking accounts, 137 were men and 151 were women. There was a significant difference between men and women regarding social networking participation, such that more women reported having social networking sites than men $\left(\chi^{2}(1, N=314)=8.22, p<.01\right)$. Two-hundred and thirty participants $(73 \%)$ reported that they have a MySpace account, 114 (36\%) reported that this is their primary account. Two-hundred and forty three participants (77\%) reported having a Facebook account, 212 (67\%) reported that this is their primary account. Of those with one or more social networking sites, $61 \%$ of participants $(n=192)$ reported that they visit a social networking site once a day or more and $23 \%(n=73)$ reported once to three times a week. When asked if their personal accounts were private, $75 \%$ of participants $(n=216)$ responded yes, $20 \%(n=58)$ responded no, and $5 \%(n=14)$ reported that they did not know. When asked how anonymous they feel their personal accounts are, $24 \%$ of participants $(n=68)$ reported "not at all," 30\% $(n=87)$ reported "a little," 34\% $(n=98)$ reported "somewhat," $11 \%(n=31)$ reported "generally," and $1 \%(n=4)$ reported that they were "very anonymous."

Regarding alcohol consumption habits, $68 \%(n=215)$ of participants report that they currently consume alcohol and $32 \%$ of participants $(n=102)$ reported that they drink alcohol once a week or more and $23 \%(n=73)$ reported that they drink once a month. Thirty three percent of participants $(n=104)$ reported that they have smoked marijuana and $10 \%(n=32)$ of participants reported that they smoke marijuana once a week or more and $5 \%(n=15)$ reported that they smoke marijuana once a month.

Table 4 summarizes the frequency with which pictures or videos of participants and their friends drinking alcohol or smoking marijuana were posted on MySpace and Facebook. First, 32\% of participants responded that they had posted a picture of themselves drinking alcohol on MySpace or Facebook. Additionally, 38\% of participants reported that a friend has posted a picture of the participant drinking alcohol on MySpace or Facebook. Furthermore, 83\% of participants reported that a friend has posted a picture of themselves drinking alcohol on MySpace or Facebook. Regarding photos of the participant smoking marijuana, only three participants reported posting one of themselves and five reported that a friend has posted a picture of the participant on MySpace or Facebook. However, $39 \%$ of participants reported that a friend had posted a picture of themselves smoking marijuana on MySpace or Facebook.

Table 4 also offers frequencies regarding video postings. Overall, 58 participants (18\%) reported having posted any kind of video on YouTube. Two participants reported having posted a video of themselves drinking alcohol and one participant reported having posted a video of themselves smoking marijuana on YouTube. All three of these videos were available for public viewing. Two participants reported that a friend posted a video of the participant drinking alcohol on YouTube and no one reported that a friend posted a video of the participant smoking marijuana on YouTube. Ten percent of participants reported that a friend posted a video of themselves drinking alcohol on YouTube and 3\% reported that a friend has posted a video of themselves smoking marijuana on YouTube.

Ninety seven percent $(n=302)$ of participants reported that they are aware of other people posting pictures of themselves drinking alcohol online. Eighty eight percent $(n=275)$ of participants reported being aware that people post pictures of themselves smoking marijuana online.

Regarding their general reactions to individuals posting pictures of themselves drinking alcohol online, the majority of participants (55\%) indicated that while potentially "stupid" or "dumb", that it was the right of the individual to decide whether or not he or she would like to have a picture of such behavior online. For example, one participant 
NOTICE: This is the author's version of a work accepted for publication by Elsevier. Changes resulting from the publishing process, including peer review, editing, corrections, structural formatting and other quality control mechanisms, may not be reflected in this document. Changes may have been made to this work since it was submitted for publication. The definitive version has been published in Computers in Human Behavior, Volume 26, Issue 6, 2010. DOI: 10.1016/j.chb.2010.04.017

explained, "I don't really care. I think that it's stupid, but they can post whatever pictures that they want if they like them." The second largest group of participants (28\%) indicated that there was no problem with posting pictures depicting alcohol use and that it can be funny or indicate social group membership. In some responses (12\%), participants qualified their acceptance by noting that they do not have a problem with people over the age of 21 posting pictures of themselves drinking because it is legal. For example, one participant wrote, "If they are underage I think its inappropriate, if they are of age then I see nothing wrong with it.” Some participants (6\%) noted that they make judgments based on what they feel was the motivation for posting the pictures. For example, one participant explained," I feel that people put pictures of themselves drinking alcohol online to try and fit in. They feel that they are normal and will be accepted if seen drinking alcohol.”

Regarding their general reactions to individuals posting pictures of themselves smoking marijuana online, the majority of participants (78\%) condemned the activity. Participants noted that the activity itself was wrong and the mere idea of posting pictures was "stupid". One participant responded, "I think these people are stupid... This can be used against them." There were more negitive responses to people posting pictures of themselevs smoking marajuna than those drinking alcohol with the explanation that drinking alcohol is legal for individuals over the age of 21, and marajuana is illegal for everyone. One participant stated, "Marijuana is illegal. I do not understand why people would take that risk of parents or bosses seeing them smoke.” The recent controversy of Olympic gold medalist Michael Phelps posting pictures of himself smoking marijuana online was also mentioned a number of times. This was used as an example of how pictures can be used against the individual. Remaining responses (22\%) indicated ambivalence or that it was the right of the individual to do as she or he pleases.

\section{Discussion}

Content analysis results revealed that both MySpace and YouTube contain public images and videos that show adolescents and young adults drinking, exhibiting inebriated behavior, or engaged in marijuana use, extending similar findings from past research on images only to video examples as well (Moreno, Parks, \& Richardson, 2007; Moreno, et al., 2009). Many behaviors consistent with known effects of alcohol consumption were presented in the sample of images and videos and most took place in social venues such as parties or bars. There was also evidence that the videos are being viewed frequently and that not only are the videos being watched, but they are being rated and commented on by an audience of YouTube members.

Questionnaire results further supported the ubiquity of such images online. The vast majority of young adults were very knowledgeable about this phenomenon, though only one-third reported engaging in these behaviors themselves. However, many more reported having friends who post pictures of alcohol-related behaviors online, reflecting similar rates to past research (e.g., Moreno, et al., 2009). Furthermore, a substantial subset of participants revealed in the their questionnaire responses that friends were posting images or videos of the participants engaged in these behaviors, a practice that was also identified in the image and video coding process.

The results also revealed interesting findings regarding potential differences between posting images of alcoholrelated behaviors and marijuana-related activities for young men and women. The majority of the images and videos identified in the content analysis were related to alcohol consumption with less images and videos of people using marijuana or drug paraphernalia. Interestingly, the majority of alcohol related images included groups of females while marijuana-related images were often individual males, potentially suggesting that marijuana use was more permissible or more of a status symbol for young men and that alcohol-related images for young women may have been posted for relationship management or information storage purposes rather than showing off (see Lee, Im, \& Taylor, 2008 for a discussion of motivations for online self-disclosure). In an associated finding, the questionnaire results revealed that students' attitudes towards alcohol-related postings suggested accepting attitudes towards this behavior, frequently not endorsing the behavior for themselves, but noting that it is okay for others to do so. Attitudes towards marijuana-related postings were much less accepting, particularly because it depicts illegal behaviors. 
NOTICE: This is the author's version of a work accepted for publication by Elsevier. Changes resulting from the publishing process, including peer review, editing, corrections, structural formatting and other quality control mechanisms, may not be reflected in this document. Changes may have been made to this work since it was submitted for publication. The definitive version has been published in Computers in Human Behavior, Volume 26, Issue 6, 2010. DOI: 10.1016/j.chb.2010.04.017

The questionnaire results also provided extended findings in several important ways. First, a quarter of participants revealed that their social networking accounts were either not private or that they were not sure of the privacy setting of their account. Furthermore, only $12 \%$ of participants viewed their social networking account as generally or very anonymous. These findings reveal lower number of accessible profiles than previous research (e.g., Fogel \& Nehmad, 2009) and perhaps a better understanding of privacy policies that previously recorded (Rifon, La Rose, \& Choi, 2005)), which may be a result of a slightly older sample, changing behavioral patterns, or social desirability in responding.

\section{Conclusions}

While the results of this study provide important information regarding the frequency and content of and attitudes towards posting images and videos of alcohol- and marijuana-related behaviors, there are some limitations to the study. First, the content analyses addressed a very small sample of such images and videos available for public access online. Second, there are other possible social media outlets for disclosing substance use, including blogs and text messages. Lastly, the questionnaire responses may have been subject to issues of social desirability, particularly regarding rates of marijuana and underage alcohol use and reports of posting marijuana-related images online, due to the illegal nature of these activities.

Future research should provide further examining social media users to assess frequency, content, and motivations behind posting images and videos of substance use online. Additionally, it would be useful to understand the potential positive as well as negative personal and professional outcomes from engaging in this phenomenon. Lastly, it would be useful for researchers to further explore interventions that could help social media users be aware of privacy policies and the potential negative outcomes of posting publicly accessible media of health risk behaviors online. Barnes (2009, p.3) found that, “...Colleges and universities are using social media to recruit and research prospective students.” As another example, Moreno, et al. (2009) found that sending a physician sponsored email to MySpace users was successful at reducing sexual references but not substance use references on users’ profiles. Other methods of increasing awareness of this phenomenon may help users better understand the implications of their behaviors and reduce its prevalence.

Overall, this study further documents the presence of publicly accessible images and videos depicting alcohol use and marijuana use on social media websites and provides an analysis of the typical content of these images and videos. While one-third of college students surveyed in this study reported having personally posted such images or videos, many more have a friend who has engaged in this behavior and almost all are aware of this phenomenon. Among this sample attitudes towards alcohol-related postings were generally accepting or positive while attitudes towards marijuana-related postings were generally negative. These results suggest that adolescents and young adults appear relatively accepting of alcohol-related activities and reveal the importance of teaching them about the potential negative outcomes related to posting these types of images and regarding the privacy settings available on social networking websites. 
NOTICE: This is the author's version of a work accepted for publication by Elsevier. Changes resulting from the publishing process, including peer review, editing, corrections, structural formatting and other quality control mechanisms, may not be reflected in this document. Changes may have been made to this work since it was submitted for publication. The definitive version has been published in Computers in Human Behavior, Volume 26, Issue 6, 2010. DOI: 10.1016/j.chb.2010.04.017

\section{References}

Anselmo, M. A., Lash, K. M., Stieb, E. S., and Haver, K. E. (2004). Cystic fibrosis on the Internet: A survey of site adherence to AMA guidelines. Pediatrics 114, 100-103.

Bandura, A. (2004). Health promotion by social cognitive means. Health Education and Behavior 31, $143-164$.

Barnes, N. (2009). Reaching the wired generation: How social media is changing college admission. Retrieved from National Association for College Admission Counseling website, http://www.nacacnet.org/publicationsresources/marketplace/discussion/ pages/socialmediadiscussionpaper.aspx

Boston Globe (2009). Is this lawman your Facebook friend? Increasingly, investigators use social networking websites for police work. Retrieved from, http://www.boston.com/news/local/articles/2009/01/11/ is_this_lawman_your_facebook_friend/?page=1.

Chiou, W. (2006). Adolescents' sexual self-disclosure on the Internet: Deindividuation and impression management. Adolescence 41, 547-561.

comScore (2009). YouTube surpasses 100 million U.S. viewers for the first time. Retrieved from, http://www.comscore.com/press/release.asp?press=2741.

Fogel, J., and Nehmad, E. (2009). Internet social network communities: Risk taking, trust, and privacy concerns. Computers in Human Behavior 25, 153-160.

Fox News (2007). Cops turn to YouTube to catch criminals. Retrieved from, http://www.foxnews.com/story/0,2933,256509,00.html.

Gibbs, J. L., Ellison, N. B., and Heino, R. D. (2006). Self-presentation in online personals: The role of anticipated future interaction, self-disclosure, and perceived success in Internet dating. Communication Research 33, 152-177.

Guadagno, R. E., Okdie, B. M., and Eno, C. A. (2008). Who blogs? Personality predictors of blogging. Computers in Human Behavior 24, 1993-2004.

Hinduja, S., and Patchin, J. W. (2007). Personal information of adolescents on the Internet: a quantitative content analysis of MySpace. Journal of Adolescence 31, 125-146. 
NOTICE: This is the author's version of a work accepted for publication by Elsevier. Changes resulting from the publishing process, including peer review, editing, corrections, structural formatting and other quality control mechanisms, may not be reflected in this document. Changes may have been made to this work since it was submitted for publication. The definitive version has been published in Computers in Human Behavior, Volume 26, Issue 6, 2010. DOI: 10.1016/j.chb.2010.04.017

Hurley, C. (2009, October 9). Y,000,000,000uTube. [Web log message]. Retrieved from http://youtubeglobal.blogspot.com/2009/10/y000000000utube.html

Inside Higher Ed. (2008). To friend or to reject. Retrieved from, http://www.insidehighered.com/ news/2009/04/29/nacac.

Joinson, A. N., and Dietz-Uhler, B. (2002). Explanations for the perpetration of and reactions to deception in a virtual community. Social Science Computer Review 20, 275-289.

Krippendorff, K. (2004). Content analysis: An introduction to its methodology (2nd ed.). Thousand Oaks, CA: Sage Publications.

Lee, D., Im, S., and Taylor, C. R., (2008). Voluntary self-disclosure of information on the internet: A multimethod study of the motivations and consequences of disclosing information on blogs. Psychology and Marketing, 25, 692-710.

Ma, M., and Agarwal, R. (2007). Through a glass darkly: Information technology design, identity verification, and knowledge contribution in online communities. Information Systems Research 18, 42-67.

Magnuson, M., and Dundes, L. (2008). Gender differences in 'social portraits' reflected in MySpace profiles. CyberPsychology \& Behavior 11, 239-241.

McKenna, K., Green, A., and Gleason, M. (2002). Relationship formation on the Internet: What's the big attraction? Journal of Social Issues 58, 9-31.

Moreno, M. A., Parks, M. R., and Richardson, L. P. (2007). What are adolescents showing the world about their health risk behaviors on MySpace? Med General Medicine 9, 9.

Moreno, M. A., Parks, M. R., Zimmerman, F. J., Brito, T. E., and Christakis, D. A. (2009). Display of health risk behaviors on MySpace by adolescents: prevalence and associations. Archives of Pediatric and Adolescent Medicine 163, 27-34.

Moreno, M. A., VanderStoep, A., Parks, M. R., Zimmerman, F. J., Kurth, A., and Christakis, D. A. (2009). Reducing at-risk adolescents’ display of risk behavior on a social networking web site. Archives of Pediatric and Adolescent Medicine 163, 35-41. 
NOTICE: This is the author's version of a work accepted for publication by Elsevier. Changes resulting from the publishing process, including peer review, editing, corrections, structural formatting and other quality control mechanisms, may not be reflected in this document. Changes may have been made to this work since it was submitted for publication. The definitive version has been published in Computers in Human Behavior, Volume 26, Issue 6, 2010. DOI: 10.1016/j.chb.2010.04.017

National Highway Traffic Safety Administration (2005). The abcs of bac: A guide to understanding blood alcohol concentration and alcohol impairment. Retrieved from, http://www.nhtsa.dot.gov/people/injury/alcohol/stopimpaired/ABCsBACWeb/images/ABCBACscr.pdf.

New York Times (2010). Arrest in Racial Case at N.J. Wal-Mart. Retrieved from, http://www.nytimes.com/2010/03/21/nyregion/21walmart.html.

Nielsen Online (2009). The global online media landscape: Identifying opportunities in a challenging market. Retrieved from, http://nielsen-online.com/emc/0904_report/nielsen-online-global-lanscapefinal1.pdf.

Nielsen Wire (2009). Time spent on Facebook up 700 but Myspace still tops for video. Retrieved from, http://blog.nielsen.com/nielsenwire/online_mobile/time-spent-on-facebook-up-700-but-myspace-still-topsfor-video/.

Raacke, J., and Bonds-Raacke, J. (2008). MySpace and Facebook: Applying the uses and gratifications theory to exploring friend-networking sites. CyberPsychology \& Behavior 11, 169-174.

Rifon, N. J., LaRose, R., and Choi, S. M. (2005). Your privacy is sealed: Effects of web privacy seals on trust and personal disclosures. The Journal of Consumer Affairs 39, 339-362.

Schmitt, K. L., Dayanum, S., and Matthias, S. (2008). Personal homepage construction as an expression of social development. Developmental Psychology 44, 496-506.

Schau, H. J., and Gilly, M. C. (2003). We are what we post? Self-presentation in personal web space. Journal of Consumer Research 30, 385-404.

SkillStorm (2009). How blogging and social networking can impact your job search. Retrieved from, http://www.skillstorm.com/blog/?p=39.

Snelson, C. and Sheffield, A. (2009). Digital storytelling in a Web 2.0 world. Proceedings of the Technology, Colleges \& Community Worldwide Online Conference (pp. 159-167). Retrieved from, http://etec.hawaii.edu/proceedings/2009/snelson.pdf.

Strauss, A. and Corbin, J. (1998). Basics of qualitative research: Techniques and procedures for developing grounded theory (2nd ed.). Thousand Oaks, CA: Sage Publications. 
NOTICE: This is the author's version of a work accepted for publication by Elsevier. Changes resulting from the publishing process, including peer review, editing, corrections, structural formatting and other quality control mechanisms, may not be reflected in this document. Changes may have been made to this work since it was submitted for publication. The definitive version has been published in Computers in Human Behavior, Volume 26, Issue 6, 2010. DOI: 10.1016/j.chb.2010.04.017

Sun P., Unger, J. B., Palmer, P. H., et al. (2005). Internet accessibility and usage among urban adolescents in Southern California: implications for Web-based health research. Cyberpsychology and Behavior 8, 441453.

YouTube (2009). Zoinks! 20 hours of video uploaded every minute, from http://www.youtube.com/blog?entry=on4EmafA5MA.

Ybarra, M. L., Mitchell, K. J., Finkelhor, D., et al. (2007). Internet prevention messages: targeting the right online behaviors. Archives of Pediatric and Adolescent Medicine 161, 138-145.

Valkenburg, P., and Peter, J. (2007). Who visits online dating sites? Exploring some characteristics of online daters. CyberPsychology \& Behavior 10, 849-852.

Walther, J. B., Van Der Heide, B., Kim, S., Westerman, D., and Tong, S. T. (2008). The role of friends’ appearance and behavior on evaluations of individuals on Facebook: Are we known by the company we keep? Human Communication Research 34, 28-49.

Zhao, S., Grasmuck, S., and Martin, J. (2008). Identity construction on Facebook: Digital empowerment in anchored relationships. Computers in Human Behavior 24, 1816-1836. 
Table 1.

Analysis of MySpace Image Descriptions.

\begin{tabular}{|c|c|c|}
\hline Category & Frequency & Image Description \\
\hline Marijuana & 32 & $\begin{array}{l}\text { Depiction of marijuana possession and use. } \\
\text { - Four images of groups, } 28 \text { of individuals } \\
\text { - } \quad \text { Five females, } 32 \text { males }\end{array}$ \\
\hline Drinking alcohol & 18 & $\begin{array}{l}\text { Individual were drinking alcohol in the image. } \\
\text { - } 10 \text { images of groups, } 8 \text { of individuals } \\
\text { - } 17 \text { females, } 11 \text { males }\end{array}$ \\
\hline Posing with alcohol & 22 & $\begin{array}{l}\text { Individuals were posing for the camera with alcohol in hand. } \\
\text { - } 15 \text { images of groups, } 6 \text { of individuals } \\
\text { - } 44 \text { females, } 10 \text { males }\end{array}$ \\
\hline Drunk & 3 & $\begin{array}{l}\text { Depictions of inebriated individuals, including: } \\
\text { - Two females and one male on couch with five wine glasses and } \\
29 \text { shots on the table. } \\
\text { - An individual male passed out with his head in a trash can. } \\
\text { - An individual male passed out on a couch. }\end{array}$ \\
\hline
\end{tabular}


Table 2.

Analysis of YouTube Video Descriptions.

Category $\quad$ Frequency Video Description

\begin{tabular}{|c|c|c|}
\hline Animal & 1 & Drunk squirrel that ate a fermented pumpkin. \\
\hline Warning & 1 & Warnings about problems associated with drinking \\
\hline Comedian & 4 & Comedians making fun of drinking. \\
\hline Marijuana & 4 & People smoking on camera or demonstrating drug paraphernalia. \\
\hline Video Log & 1 & Candid video diary about personal alcohol and drug use. \\
\hline Scenes of & 64 & Behaviors consistent with alcohol consumption shown in videos: \\
\hline Drinking or & & - $\quad$ Speech: Slurred speech when talking. \\
\hline \multirow[t]{12}{*}{ Inebriation } & & - $\quad$ Loss of muscle coordination: Staggering, clumsy behaviors. \\
\hline & & - $\quad$ Mood change: laughing, singing, dancing \\
\hline & & - $\quad$ Impaired judgment: attempt to put on pants as a shirt. \\
\hline & & - Loss of inhibition: public urination, a man bending over to let others kick \\
\hline & & him in the rear. \\
\hline & & - $\quad$ Sick: moaning on the floor, vomiting, unable to get up. \\
\hline & & - Unconscious: laying on floor or couch passed out. \\
\hline & & Other behaviors: \\
\hline & & - Consumption of alcohol: Drinking from bottles or glasses. \\
\hline & & - $\quad$ Admission of drunkenness: saying that people are drunk. \\
\hline & & - $\quad$ People playing tricks on friend or stranger who is drunk. \\
\hline & & - $\quad$ Peers helping a drunk friend who is sick or very inebriated. \\
\hline
\end{tabular}


NOTICE: This is the author's version of a work accepted for publication by Elsevier. Changes resulting from the publishing process, including peer review, editing, corrections, structural formatting and other quality control mechanisms, may not be reflected in this document. Changes may have been made to this work since it was submitted for publication. The definitive version has been published in Computers in Human Behavior, Volume 26, Issue 6, 2010. DOI: 10.1016/j.chb.2010.04.017

Table 3.

Additional Descriptive Data for YouTube Video Sample ( $N=75)$.

\begin{tabular}{lcccc} 
& Mean & SD & Min & Max \\
\hline Duration in Minutes & $3: 01$ & $2: 34$ & $0: 15$ & $11: 06$ \\
Number of Views & 109,434 & 564,491 & 17 & $3,778,820$ \\
Number of Ratings & 285 & 1,308 & 0 & 8,510 \\
Number of Stars & 3.3 & 1.8 & 0.0 & 5.0 \\
Number of Comments & 221 & 1,073 & 0 & 7,060 \\
Use Age & 24 & 5 & 17 & 40 \\
Days Online* & 397 & 352 & 1 & 1,107
\end{tabular}

Note: Days online between oldest and newest video in the sample. Date span = Feb. 6, 2006 to March 2, 2009. 
NOTICE: This is the author's version of a work accepted for publication by Elsevier. Changes resulting from the publishing process, including peer review, editing, corrections, structural formatting and other quality control mechanisms, may not be reflected in this document. Changes may have been made to this work since it was submitted for publication. The definitive version has been published in Computers in Human Behavior, Volume 26, Issue 6, 2010. DOI: 10.1016/j.chb.2010.04.017

Table 4.

Frequencies of Self-Reported Alcohol and Marijuana Image and Video Postings on Social Networking Websites (N= 314).

\begin{tabular}{|c|c|c|c|}
\hline Posting Type & MySpace & Facebook & YouTube \\
\hline & (Picture) & (Picture) & (Video) \\
\hline
\end{tabular}

Posted by self of self

\begin{tabular}{|c|c|c|c|}
\hline Drinking Alcohol & $81(26 \%)$ & $54(17 \%)$ & $2(<1 \%)$ \\
\hline Smoking Marijuana & $2(<1 \%)$ & $1(<1 \%)$ & $1(<1 \%)$ \\
\hline
\end{tabular}

Posted by friend of self

Drinking Alcohol

Smoking Marijuana

Posted by friend of friend

Drinking Alcohol

Smoking Marijuana
103 (30\%)

$2(<1 \%)$

258 (75\%)

$114(33 \%)$
70 (29\%)

$3(1 \%)$

$229(67 \%)$

85 (25\%)
$2(<1 \%)$

0

Note: 230 participants have a MySpace account, 243 participants have a Facebook account, and 58 participants have posted a video on YouTube. 